\title{
NEW REMEDIES FROM NATURAL PRODUCTS IN BRAIN STROKE
}

\author{
Dr. Haushila Prasad Pandey ${ }^{1 *}$, Dr. Vaibhav Mishra ${ }^{2}$, and Dr. Akanksha ${ }^{3}$
}

\section{ABSTRACT:}

\section{INTRODUCTION:}

Acute ischemic stroke is the third leading cause of death and the most frequent cause of permanent disability. Despite advances in the understanding of the pathophysiology of cerebral ischemia, therapeutic options remain limited. Only recombinant tissue-plasminogen activator (rt-PA) for thrombolysis is currently approved for use in the treatment of stroke. However, its use is limited by its short therapeutic window (three hours), complications derived essentially from the risk of haemorrhage, and the potential damage from reperfusion/ischemic injury. Two important pathophysiological mechanisms involved during ischemic stroke are oxidative stress and inflammation ${ }^{3}$. On the basis of pre existing literatures, brain tissue is not well equipped with antioxidant defenses. So for a future candidate drug that may able to cure the stroke it must have anti oxidant and anti inflammatory properties. This review will discuss the molecular and biochemical aspects of oxidative stress and inflammation in ischemic stroke that targets neuro-inflammation through natural products.

\section{KEYWORDS :}

Apoptosis; Ischemia; Stroke; Brain; Neuro-inflammation

1. Professor and Head of the Department of Biochemistry, Universal College of Medical Sciences \& Teaching Hospital, Bhairahawa, Nepal

2. Department of Environmental Microbiology, Babasaheb Bhimrao Ambedkar University, Lucknow-226031, India

3. Division of Microbiology, CSIR-Central Drug Research Institute, Lucknow-226001, India

\author{
For Correspondence: \\ Dr. Haushila Prasad Pandey \\ Professor and Head of the Department of Biochemistry, \\ Universal College of Medical Sciences \& Teaching \\ Hospital, Bhairahawa, Nepal \\ E.mail: hppandey2010@gmail.com
}




\section{INTRODUCTION:}

Stroke also known as cerebro-vascular accident causes loss of brain function by reduction of blood supply and that consequential decreases oxygen tension and accumulation of high-energy metabolites in the affected part of the brain that are responsible for sudden symptom. This can be due to ischemia caused by blockage (thrombosis, arterial embolism), or a hemorrhage. Ischemic stroke is the second most dangerous disease that causes death and also one of the major factors for disability of human being ${ }^{9}$. 36 . It deadly affected the normal healthy life. It is usually referred to a condition caused by the occlusion or haemorrhage of blood vessels supplying the brain ${ }^{8}$. The males are more prone to incidence of stroke and it is 1.25 times higher than females and the difference is somewhat larger at younger age but not at older age. The male/female incidence was 1.59 for ages 6569 ; 1.46 for age $7074 ; 1.35$ for age 7579 and 0.74 for age 80 and older (Heart Disease and Stroke Statistics-2006 Update, American Heart Association). There is less awareness about the stroke although they are more debilitating. Studies show that on an average, a person waits for 13 hours after experiencing the first symptoms of stroke before seeking medical care. Forty two percent patients wait for as long as 24 hours. Therefore, awareness on the issue is a must because it is critical to recognise the symptoms of stroke and seek immediate emergency attention.

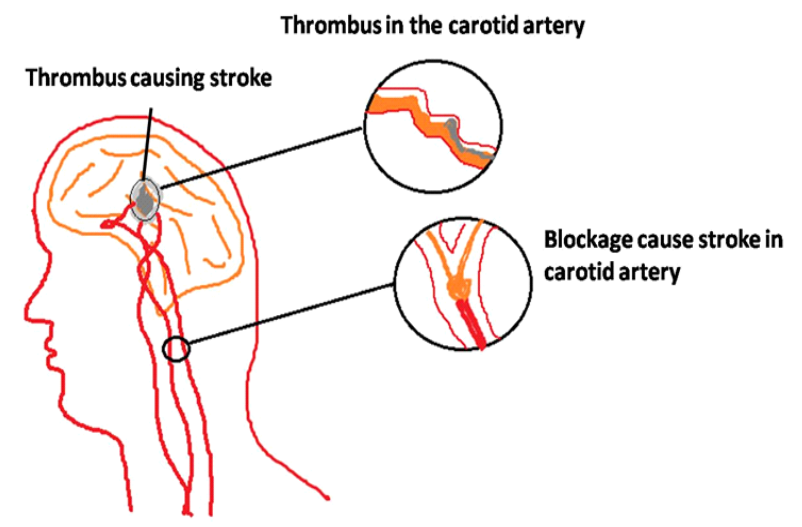

Figure: Pictorial image depicts how the stroke occurs due to the occlusion in carotid artery. (Copyright image of Dr. Vaibhav Mishra, one of the co-author to the present review article)

\section{WORLD-WIDE MORBIDITY AND MORTALITY ASSOCIATED WITH STROKE:}

Stroke is the second highest reason of mortality with an approximate 5.7 million deaths in 2005 and $87 \%$ of these deaths were in poor and developing nations. Without intervention, the number of global deaths is projected to rise to 6.5 million in 2015 and to 7.8 million in $2030^{36}$.

WHO estimated that over 70 million healthy life-years across the globe will be affected by 2020 as a result of stroke, and $90 \%$ of this burden will be expanding in developing countries 36

400-800 strokes cases are occurred with per 100,000 people Annually 5.7 million deaths ${ }^{37}$

15 million new acute strokes every year

28,500,000 DALYs (disability adjusted life-year) (WHO 2004)

$28-30$ day case fatality ranges from $17 \%-35 \%{ }^{11}$

STROKE MORBIDITYAND MORTALITY IN INDIA: According to World Health Organization (WHO) 130 per 100,000 people of India are suffering from stroke every year. Prevalence 55.6 per 100,000 all ages ${ }^{4} 0.63$ million deaths (WHO 2005) 1.44-1.64 million cases of new acute strokes every year (WHO 2005)6,398,000 DALYs (WHO 2009)

$12 \%$ of strokes occur in the population aged $<40$ years $^{5} 28-30$ day case fatality ranges from $18-41 \%{ }^{4 \& 6}$

India stands in high mortality zone for stroke as per atlas of heart disease and stroke ${ }^{25}$. Brain stroke is the third largest killer in India after heart attack and cancer. It is the second highest cause of mortality with an estimated $7 \cdot 5$ million deaths in 2010 and $87 \%$ of these deaths were in poor and developing nations. But, there is less awareness about the same even though they are more debilitating. Therefore, awareness on the issue is a must because it is critical to recognize the symptoms of stroke and seek immediate emergency attention.

Approximately 20 million people each year will suffer from stroke and of these 5 million will not survive ${ }^{4}$. Effective screening, evaluation, and management strategies for stroke are well established in high-income countries, but these strategies have not been fully implemented in India ${ }^{31}$. In india, $15 \%$ of strokes occur in the population aged $<40$ years.

\section{CEREBRAL STROKE AND FREE RADICALS:}

Reactive oxygen species is associated with many neurodegenerative diseases and brain disorders. Free radicals are responsible for brain dysfunction because it is actively participating in reperfusion injury after stroke ${ }^{19}$. The brain utilizes $15 \%$ of the energy generated in the body to maintain ionic gradient, synthetic and catabolic activity exclusively through oxidative phosphorylation. As the brain has poor capacity to store energy, so it requires a constant supply of oxygenated blood to maintain its functional and structural integrity. A drop in CBF, hypoxia, protracted hypoglycaemia and severe anaemia can cause critical shortage of cellular energy. This lack of energy initially causes ionic and electrical failure leading to cascade of molecular and cellular events that includes glutamate excito-toxicity, perturbation of calcium homeostasis, oxidative stress, dysfunction of mitochondria and endoplasmic reticulum, alteration in gene expression, activation of cysteine proteases (caspases) and endonucleases $^{15}$. These enzymes rapidly dismantle the important structural and regulatory components of the cell.

\section{GENES INVOLVED IN APOPTOSIS OF NEURONS IN ISCHEMIC BRAIN STROKE:}

The stroke causes severe damage to brain due to apoptosis. The key proteins in apoptosis are caspases, a group of aspartate-specific cysteine proteases and its activation is 
regulated by Bcl-2 family proteins. Bcl-2 is a family of evolutionarily related proteins. These proteins govern mitochondrial outer membrane permeabilization (MOMP) and can be either pro-apoptotic (Bax, BAD, Bak and Bok among others) or anti-apoptotic (including Bcl-2 proper, Bcl$\mathrm{xL}$, and Bcl-w, among an assortment of others). Bcl-2 is expressed in cells that survive fatal development ${ }^{26}$, and it inhibits programmed cell death in many in vitro systems ${ }^{38}$. These proteins will likely emerge as molecular targets in future for the treatment of cerebral stroke. Recent studies have suggested that bcl-2 proteins play an important role in regulation of the apoptotic pathway. However, their roles in cerebral ischemia are not yet clearly understood and needed to be explored in greater details.

\section{ROLE OF APOPTOSIS AND NECROSIS IN ISCHEMIC STROKE:}

Apoptosis and necrosis are two main phenomena in cell death $^{39,18 \& 22}$. Apoptosis and necrosis are extremely crucial for cell development and survival in neurological diseases and they both have distinguished mechanisms ${ }^{33}$. Necrosis causes a direct effect on injured/damaged cell and the cell begin to die. On the other hand, some cascade events / mild stimuli are responsible for apoptotic events like death receptors and some protein complexes ${ }^{16}$. Necrosis occurs in areas that are severely affected by the injury. Cell death events depend on temperature exposure e.g. $43^{\circ} \mathrm{C}-45^{\circ} \mathrm{C}$ temperature is responsible for apoptosis and higher temperatures are responsible for necrosis in murine P-815 cell ${ }^{13}$. Acute and chronic neurodegenerative disorders are characterized by apoptosis ${ }^{13,40 \& 23}$.

\section{NEURONAL DAMAGE IN STROKE:}

Neuronal damage is associated with acidosis ${ }^{16}$. Ischemia injury induced neuroinflammation causes early damage in brain tissue. Translocation of Phosphatidyl serine to outer leaflet is the characteristic feature of early apoptotic cell death $^{5}$.Apoptosis waste elimination is one of the main features of early apoptosis events. The increase in the number of apoptotic cells in the cortical region indicating the delayed infarction in this region is mainly due to apoptosis and constitutes the boundary zone of the ischemic core. This may also reflect the reduction of $\mathrm{CBF}$ and arterial distribution. Therefore, in such regions ATP levels are conserved to carry out intrinsic neuroprotective mechanisms for survival of the cells as observed by significant increase in the number of apoptotic neurons in the cortex. Striatum is the most affected brain region following ischemic stroke. Cerebral infarction, neurons which undergoes necrosis and complex signalling pathways are the main reason for striatum tissue damage. Additionally, neuronal injury in the striatal and cortical region may also depend upon the vulnerability of neurons to ischemic stress.

Delayed neuronal fatality occurs in transient ischemia of brain $^{29}$. According to recent studies protein inhibitors play a major role in delayed cell death through the apoptosis activation $^{29}, 30 \& 35$. In cerebral ischemic necrosis occurs in the core of the lesion and there is apoptotic cell death in the penumbra ${ }^{20} \& 24$. The present review reveals that, natural products treatment could prevent or diminish tissue damages of both the cortex and the striatum caused by cerebral ischemia/reperfusion (I/R) injury ${ }^{6}$.

\section{ROLE OF CYCLOOXYGENASE ENZYME IN ISCHEMIC STROKE:}

Cyclooxygenases are present in different isoforms like Cox 1 , Cox-2 and Cox-3. Cox-1 is housekeeping gene whereas Cox-3 is formed by constitutive genes Cox-1 and it is not functional in human beings and act like housekeeping proteins. In previous studies on rodents it has been found that Cox-3 is selectively inhibited by phenacetin, paracetamol, antipyrine and some NSAIDs. Then after literature survey, we found that Cox-2 is major enzyme and it plays an important role in brain stroke. Cox-2 expression in brain has been associated with pro-inflammatory activities, thought to be instrumental in neurodegenerative processes of several acute and chronic diseases. Present review, therefore, is an attempt to reveal the role of mitochondrial dysfunction to downstream cell death activation pathways mediated by Cox-2, since it was assumed that Cox-2 activation alone may not be able to culminate into increased cellular damage in stroke. Further, the role of reactive oxygen species (ROS) in cellular damage has been analyzed using natural extracts, which have antioxidant property. Further studies will be undertaken to analyze the role of cyclooxygenase enzymes Cox-2 and apoptotic gene like Bcl-2 to analyze caspase-dependent and independent apoptotic mechanisms following mitochondrial dysfunction. These findings may be helpful in understanding the basic events involved in free radical generation and oxidative stress induced cell survival/death signalling pathways during I/R injury ${ }^{6}$.

\section{APPEAL FOR HERBAL THERAPY:}

Therefore, there is a great need to understand the molecular and biochemical mechanisms underlying neuronal death and survival. The future challenge of stroke therapy is to translate the basic pathophysiological evidence of ischemic neuronal injury into novel neuroprotective therapies either independent or in combination with thrombolytic drugs ${ }^{6}$. Therefore, research is being focused on to develop novel therapies that may act upon the signal transduction mechanisms mediating stroke damage. Nevertheless, this is influenced by alterations in gene expression. Hence, proper and better understanding of cerebral ischemia induced gene expression may help to target the long-term function of the brain? .

Although there are drugs available that can dissolve a clot, for acute stroke patients requiring thrombolysis, currently no strategies exist to prevent or limit ischemic damage resulting from the stroke. Therefore, a detailed understanding of the molecular mechanisms resulting in cell death during cerebral ischemia/reperfusion $(\mathrm{I} / \mathrm{R})$ injury may provide a more realistic picture for future stroke treatments. $I / R$ injury triggers multiple and distinct but overlapping cell signalling pathways, which may lead to cell survival or cell damage. There is overwhelming evidence which suggests that besides necrosis, apoptosis do contributes significantly to the cell death subsequent to $\mathrm{I} / \mathrm{R}$ injury ${ }^{27}$. Both extrinsic and intrinsic 
apoptotic pathways play a vital role, and upon initiation, these pathways recruit downstream apoptotic molecules to execute cell death. All instances of cell survival/death mechanisms triggered during I/R injury are multifaceted and interlinked, which ultimately decide the fate of brain cells. Many drugs aiming at excitotoxicity and oxidative stress have not been successful in clinical trials. Because, the pathology of ischemic stroke is complex and any approach targeting a single mechanism may not provide a general effective therapy for stroke patients. Moreover, apoptotic cross-talk between major subcellular organelles suggests that therapeutic strategies should be optimally directed at multiple targets/mechanisms for better therapeutic outcome.

\section{NEED OF SCIENTIFIC APPROACH FOR THE DEVELOPMENT OF ANTI-STROKE AGENTS:}

In order to overcome these adverse effects, investigation has been extended for the search of new and novel molecules from plant sources which can show better protection with lower rate of incidences of relapse. It has long been recognized that natural product structures have the characteristics of high chemical diversity, biochemical specificity and other molecular properties that make them favourable as lead structures for the remedies of a number of disorders including stroke .

Drugs from indigenous sources of natural products are now a target for development, refinement and pharmacological modification for anti-stroke treatment. Natural products structurally have characteristic high chemical diversity, biochemical specificity and other medicinal properties that make them favourable as lead structures for the remedies of a number of disorders including anti-ulcer activity. Ayurveda, which literally means the Science of life, is one of the oldest systems of medicines in India. This system of using natural resources for betterment of health was developed through the experimentation and experiences of day-to-day life style of Indian people. But scientific evidence to prove the rationale of using these formulations in health care is essential to develop. Various Indian medicinal plants like Cucurma longa, Zingiber officinale, Ginkgo Biloba, Allium sativum and Emblica Officinalis ${ }^{6}$ etc. have been reported to possess anti-stroke activity. We have directed our endeavours towards establishing the scientific rational in governing the efficacy of natural products in stroke treatment, using literature survey to explore their anti-stroke and healing properties.

Natural products are frequently used in traditional Indian medicine and widely used to treat many diseases. Cerebral stroke has emerged as one of the largest reasons of disability world-wide and cause deleterious effects on normal healthy life $^{2}$. The brain ischemic injury involves so many mechanisms. Some studies demonstrated that severe transient ischemia serves worse compared to permanent ischemia ${ }^{1428}$. The cell death examination is an important factor in cerebral stroke for ${ }_{17 \& 34}$ the study of morphological and biochemical changes in cell ${ }^{32}$,

\section{CONCLUSION:}

The main aim of this review is to find out the involvement of natural products in neuronal apoptosis, neuro-degeneration and effect of its compounds in brain stroke that may provide better anti-stroke drug. However, current therapeutics, essentially had anti inflammatory effects. The drugs, which may interact with the ongoing neuropathological processes in the brain in addition to having a symptomatic effect, may be more beneficial in hindering the progression of the disease. So need of new chemical entities (NCEs) for health care is investigated and served through the plant sources. In almost all the traditional systems of medicine, the medicinal plants play major roles and constitute their backbone. Indian medicinal plants possess enormous healing power and only a part of this potentiality is known to mankind. Evolution of Ayurveda and plant-based remedies for health care through day-to-day life experiences is a part of the cultural heritage of India. Scientific evidence to prove the rationale of using these formulations in health care is essential to develop. Compounds isolated from natural products may be extremely helpful and important to develop a potential drug to be used against stroke treatment, and further investigation of potential natural compounds against ongoing neurodegenerative processes, can be more beneficial and pragmatic approach for overall therapy of stroke.

\section{REFERENCES:}

1. Banerjee, A., Lakshmi, I. History, Institutions, and Economic Performance: The Legacy of Colonial Land Tenure Systems in India. Amer Eco Rev,95(4):1190-1213,(2005).

2. Bhandari U, Ansari MN. Protective effect of aqueous extract of Embelia ribes Burm fruits in middle cerebral artery occlusioninduced focal cerebral ischemia in rats. Indian J Pharmacol, 40 (5):215-20,(2008)

3. Coyle, JT, Puttfarcken P. Oxidative stress, glutamate, and neurodegenerative disorders. Science. 262(5134):68995,(1993).

4. Dalal, PM. Stroke Epidemic in India - Journal of the Association of Physicians of India (2007).

5. Denecker G, Dooms H, Van LG, Vercammen D, Grooten J, Fiers $W$, Declercq W, Vandenabeele P. Phosphatidyl serine exposure during apoptosis precedes release of cytochrome $c$ and decrease in mitochondrial transmembrane potential. FEBS Lett, 465(1): 47-52,(2000).

6. Dinesh tripathi, Arti verma, Sandeep bhattacharya and Tiwari S. Effect of Emblica officinalis (amla) on apoptotic cell death following ischemia reperfusion injury in rats. Int J Pharm Bio Sci, 6(3):(B) 81 87,(2015).

7. Ebrahim, S, Sung, J, Song, YM., Ferrer, RL., Lawlor, DA., Davey Smith G. Serum cholesterol, haemorrhagic stroke, ischaemic stroke, and myocardial infarction: Korean national health system prospective cohort study. BMJ.333(7557):22, (2006).

8. Eng JJ, Chu KS, Kim CM, Dawson AS, Carswell A, Hepburn KE. A community-based group exercise program for persons with chronic stroke. Med Sci Sports Exerc, 35(8):1271-8,(2003).

9. Feigin, VL. Stroke epidemiology in the developing world. Lancet $1 ; 365(9478): 2160-1,(2005)$ 
10. Friedlander RM. Apoptosis and caspases in neurodegenerative diseases. NEnglJMed, 348(14):1365-75,(2003).

11. Feigin, VL, Lawes, CM., Bennett, DA., Barker-Collo SL., Parag $V$. Worldwide stroke incidence and early case fatality reported in 56 population-based studies: a systematic review. Lancet Neurol 8(4):355-69,(2009).

12. Goto K, Ishige A, Sekiguchi K, Iizuka S, Sugimoto A, Yuzurihara $M$, Aburada M, Hosoya E, Kogure K. Effects of cycloheximide on delayed neuronal death in rat hippocampus. Brain Res, 534(12):299-302,(1990).

13. Harmon BV, Corder AM, Collins RJ, Gobe GC, Allen J, Allan DJ, Kerr JF. Cell death induced in a murine mastocytoma by 42-47 degrees $C$ heating in vitro: evidence that the form of death changes from apoptosis to necrosis above a critical heat load. Int JRad Biol, 58(5):845-858,(1990).

14. Hossmann, K.A. and Zimmermann, V. Resuscitation of the monkey brain after $1 \mathrm{~h}$ complete ischemia, I: physiological and morphological observations.Brain Res, 81(1): 59-74,(1974).

15. Hou, ST., MacManus, JP. Molecular mechanisms of cerebral ischemia-induced neuronal death. Int Rev Cytol, 221:93148,(2002).

16. Huang Y, McNamara JO. Ischemic stroke: "acidotoxicity" is a perpetrator. Cell, 118(6):665-666,(2004).

17. Kerr JFR, Wyllie AH, Currie AR. Apoptosis, a basic biological phenomenon with wide-ranging implications in tissue kinetics. BrJCancer 26(4):239-245,(1972).

18. Kanduc D, Mittelman A, Serpico R. Cell death: apoptosis versus necrosis. Int JOncol, 21(1):165-70,(2002).

19. Kontos, Induced Cerebral Arteriolar Dilation after Acute Hypertension, (1985).

20. Linnik MD, Zobrist RH, Hatfield MD. Evidence supporting a role for programmed cell death in focal cerebral ischemia in rats. Stroke, 24(12):2002-2009,(1993).

21. Li Y, Chopp M, Jiang N, Zaloga C.,In situ detection of DNA fragmentation after focal cerebral ischemia in mice. Brain Res Mol Brain Res, 28(1):164-168,(1995).

22. Martin LJ. Neuronal cell death in nervous system development, disease, and injury. Int J Mol Med, 7(5):455-78,(2001).

23. Martin JB. Molecular basis of the neurodegenerative disorders. NEngl JMed, 340(25): 1970-1980,(1999).

24. MacManus JP, Buchan AM, Hill IE, Rasquinha I, Preston E. Global ischemia can cause DNA fragmentation indicative of apoptosis in rat brain. Neurosci Lett, 164(1-2):89-92,(1993).
25. Mackay, J. and Mensah, G. A. The atlas of heart disease and stroke. World Health Organization, p1-112,(2004).

26. Novack and Korsmeyer. Apoptosis in Toxicology, (1994).

27. Nakka et al Apoptosis: Involvement of Oxidative Stress and Intracellular $\mathrm{Ca} 2+$

28. Nordstron, C.H., Rehncrona, S. and Siesjo, B.K. Restitution of cerebral energy state after complete and incomplete ischemia of 30 min duration. Acta Physiol Scand, 97(2): 270-272, (1976).

29. Pulsinelli WA, Brierly lB, Plum F. Temporal profile of neuronal damage in a model of transient forebrain ischemia. Ann Neurol, 11(5):491-498,(1982)

30. Papas S, Crepel V, Hasboun D, Jorquera I, Chinestra P, Ben-Ari $Y$. Cycloheximide reduces the effects of anoxic insult in vivo and in vitro. Eur JNeurosci,4(8):758-765,(1992).

31. Pandian, JD. Stroke and thrombolysis in India 55(2):173,(2007).

32. Rubin LL. Neuronal cell death: when, why and how. Br Med Bull, 53(3):617-631,(1997)

33. Raff MC, Barres BA, Burne JF, Coles HS, Ishizaki Y, Jacobson MD. Programmed cell death and the control of cell survival: lessons from the nervous system. Science, 262(5134):695700,(1993).

34. Server AC, Mobley WC. Neuronal cell death and the role of apoptosis. In: Tomei LD, Cope FO (eds.), Apoptosis: The Molecular Basis of Cell Death. Cold Spring Harbor, NY: Cold Spring Harbor Laboratory Press: 1991,pp.263-278.

35. Shigeno T, Yamasaki Y, Kato G, Kusaka K, Mirna T, Takakura K, Graham Dl, Furukawa S. Reduction of delayed neuronal death by inhibition of protein synthesis. Neurosci Lett, 120(1):117119,(1990).

36. Strong, K. Preventing stroke: saving lives around the world. Lancet Neurol, 6,182-187,2007

37. Sridharan, SE., Unnikrishnan, JP., Sukumaran, S., Sylaja, PN., Nayak, SD., Sarma, PS., Radhakrishnan, K. Incidence, types, risk factors, and outcome of stroke in a developing country: the Trivandrum Stroke Registry. Stroke 40(4):1212-8,(2009).

38. Vaux, DL., Cory, S., Adams, JM. Bcl-2 gene promotes haemopoietic cell survival and cooperates with c-myc to immortalize pre-B cells. Nature. 335(6189):440-2,(1988).

39. Wyllie AH, Kerr JF, Currie AR. Cell death: the significance of apoptosis. Int Rev Cytol, 68:251-306,(1980). Yuan J, Yankner BA. Apoptosis in the nervous system. Nature, 407(6805):802-809,(2000). 